\title{
THE VIRTUAL CHECK RIDE (VCR) AS A DIAGNOSTIC AND REMEDIATION SYSTEM
}

\author{
Ron Tarr \& James D. Whitmire II \\ Institute for Simulation and Training \\ Orlando, FL, USA \\ E-mail: jwhitmire@cfl.rr.com
}

\begin{abstract}
Summary: The Florida Department of Transportation (FDOT) and the U.S. Department of Transportation (US DOT) have identified safety and operator performance as major objectives in addressing the inter-modal transportation needs of the state and nation. The Florida Department of Highway Safety and Motor Vehicles is working diligently to address the issue of safety on Florida's roads by developing and enforcing standards and certification of Commercial Driver License (CDL) training and issuance, as well as continual monitoring via enforcement. The Florida Trucking Association (FTA), representing the commercial industry side of the community, is likewise very concerned and is also taking steps to deal with these challenges. Clearly the issue of safety and the proper training of persons who will be operating heavy trucks is of great concern to all of us in the community. Driver training, safety, security, performance enhancements and accident reduction are priority issues in the truck driving industry. With this emphasis, and the increase in highway safety compromised by fraudulent or unskilled CDL licensed drivers, the new Virtual Check Ride, a simulated knowledge and skilled-based diagnostic system for professional truck drivers, was created using multimedia blended simulation that includes computerbased training (CBT) elements. This system also utilizes the GE VS TruckDriving Simulator. While the implications of VCR are rich with possibilities, the goal of this research is to validate and verify the newest version of the VCR system within the trucking community (e.g., Frito Lay and others).
\end{abstract}

\section{VIRTUAL CHECK RIDE OVERVIEW}

The Virtual Check-Ride System computer-based training (CBT) section reflects the requirements set forth by the CDL testing process for the class A, B and C driver's license. In addition, the class E driver's license test is being incorporated into the diagnostic and remediation system. However, the thrust of this paper explores the class A driver's test, which consists of two tests: the Knowledge test and the Virtual Pre-Trip Inspection. When an individual sits down at the computer to take the test, they start with the Knowledge Test and flow linearly though the three different sections as they would in the actual CDL test. The CBT system tracks the scores for each section and provides a percentage for each, as well as an overall score. The overall score must be $80 \%$ or higher in order to move on to the Virtual Pre-Trip Inspection. Should the overall score of $80 \%$ not be achieved, the individual must retake the sections of the knowledge test where deficiencies were noted in order to move on. Upon completion of the Knowledge Test (see Figure 1), the driver will then continue on to the Virtual Pre-Trip (Figure 2). 


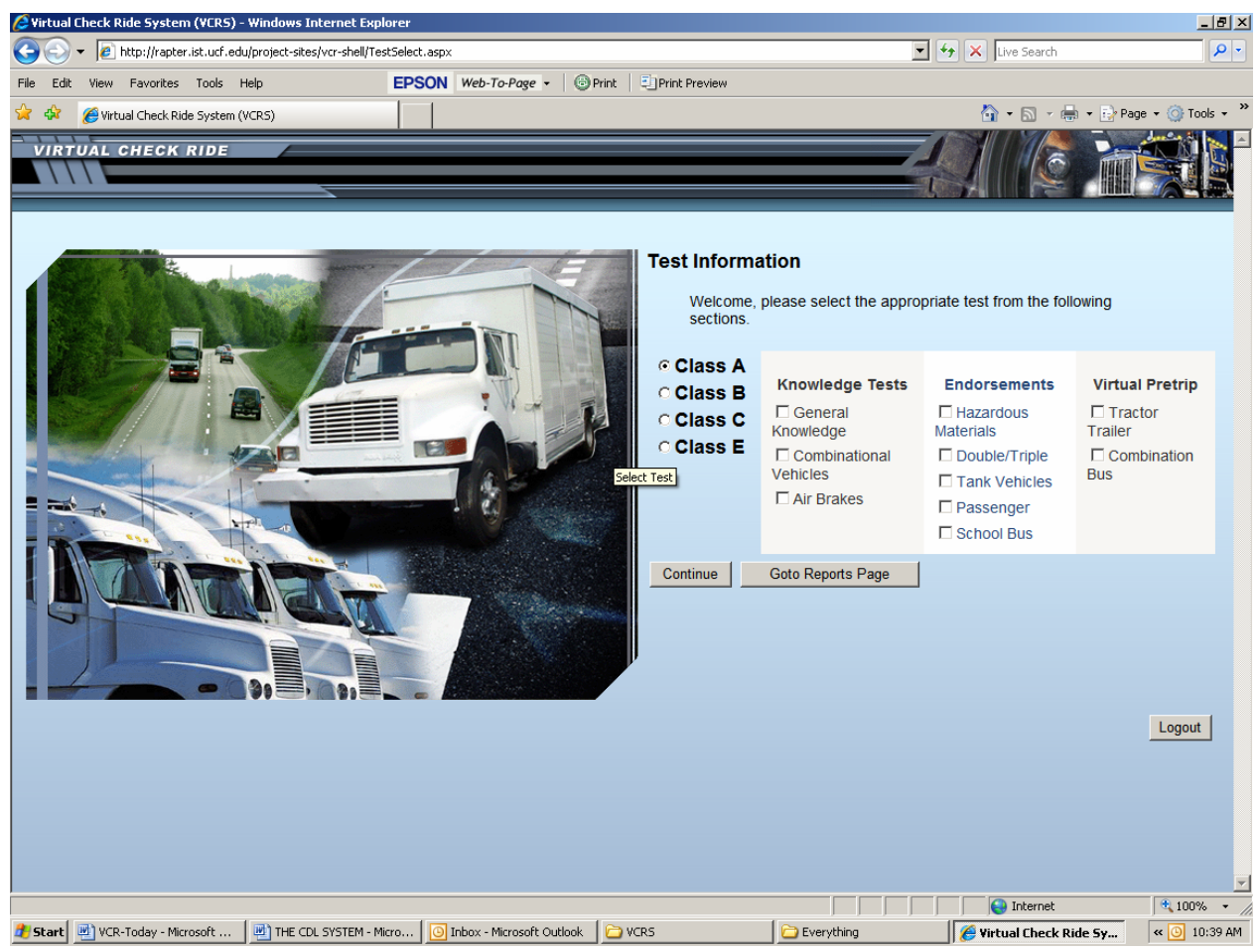

Figure 1. Knowledge Test

The Virtual Pre-Trip Inspection is a 'part identification' test that assesses the driver's knowledge on part location and name. After the part identification is addressed, a series of questions on possible defects pertaining to that particular part are presented to the driver trainee. The test is comprised of the 117 inspection points, and a driver must match the part with its correct name. To pass the Virtual Pre-Trip Inspection, a driver must identify a minimum of 83 inspection points. Should the driver not identify at least 83 inspection points, a report will be generated that identifies the parts that were not identified correctly and the report can be used as a study guide to help the driver focus on areas of concern.

Upon completion, the driver will move on to the previously validated, simulated driving scenarios, and their performance will be assessed by a third-party examiner. The third-party examiner will perform their duties as they would in an actual truck, and the driver will be asked to drive through the different types of driving conditions mandated by the CDL process. The different areas are: on-pad driving maneuvers and off-pad driving skills assessment, which consist of urban driving, city driving and rural driving. The third party examiner will assess the driver as they would in an actual real-world driving environment and pass or fail the driver. Should the driver fail, they will have to re-do the entire simulated driving scenarios at a later time. 


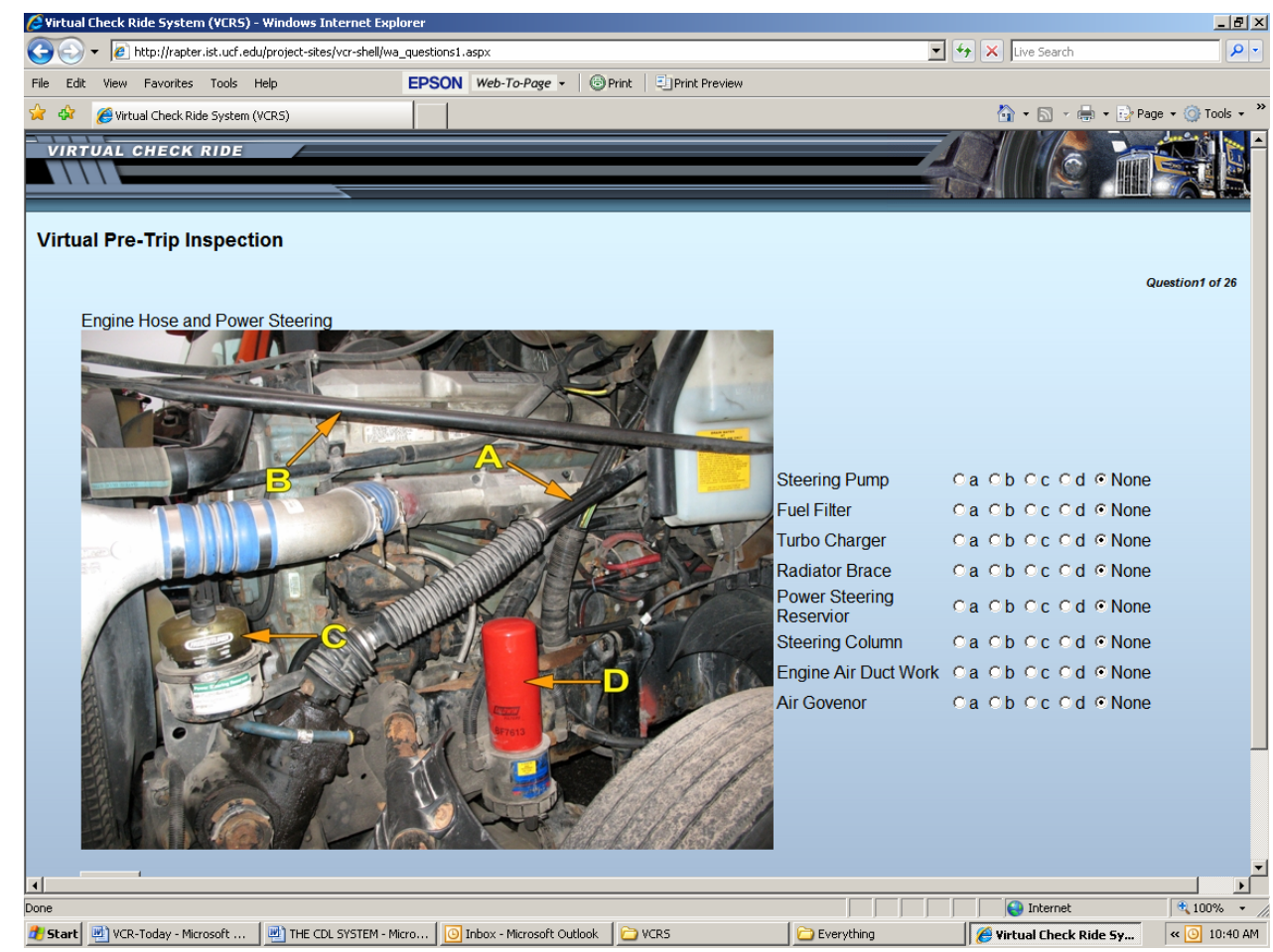

Figure 2. Virtual Pre-Trip

\section{VIRTUAL CHECK RIDE REMEDIATION}

The current CDL driver's manual questions are designed to test drivers in the areas listed in Table 1; however, at the conclusion of the test, no feedback is given to the potential CDL driver. The Virtual Check Ride (VCR) diagnostic and remediation system identifies weaknesses in these skill areas through specific questions and takes the driver through web-based links to the specific area in the CDL manual that may address the driver's weakness.

\section{Table 1. Skill Areas}

\begin{tabular}{|c|c|c|c|}
\hline Vehicle Inspection & $\begin{array}{c}\text { Basic Control of Your } \\
\text { Vehicle }\end{array}$ & Shifting Gears & Seeing \\
\hline Communicating & Space Management & $\begin{array}{c}\text { Controlling Your } \\
\text { Speed }\end{array}$ & Seeing Hazards \\
\hline Distracted Driving & $\begin{array}{c}\text { Aggressive } \\
\text { Drivers/Road Rage }\end{array}$ & Night Driving & Driving in Fog \\
\hline Winter Driving & Hot Weather Driving & $\begin{array}{c}\text { Railroad-highway } \\
\text { Crossings }\end{array}$ & Mountain Driving \\
\hline Driving Emergencies & Antilock Braking & $\begin{array}{c}\text { Skid Control and } \\
\text { Recovery }\end{array}$ & Accident Procedures \\
\hline & Flcohol, Other Drugs, \\
and Driving & $\begin{array}{c}\text { Staying Alert and Fit } \\
\text { to Drive }\end{array}$ & $\begin{array}{c}\text { Hazardous Materials } \\
\text { Rules }\end{array}$ \\
\hline
\end{tabular}


Figure 3 illustrates the user interface for CDL remediation. It gives the driver trainee feedback on what section the question came from, as well as the skill area within that particular domain. The section titles are hyperlinked to the appropriate topics in the CDL manual. Further remediation is being developed to address skill areas by directing the driver trainee to appropriate training modules.

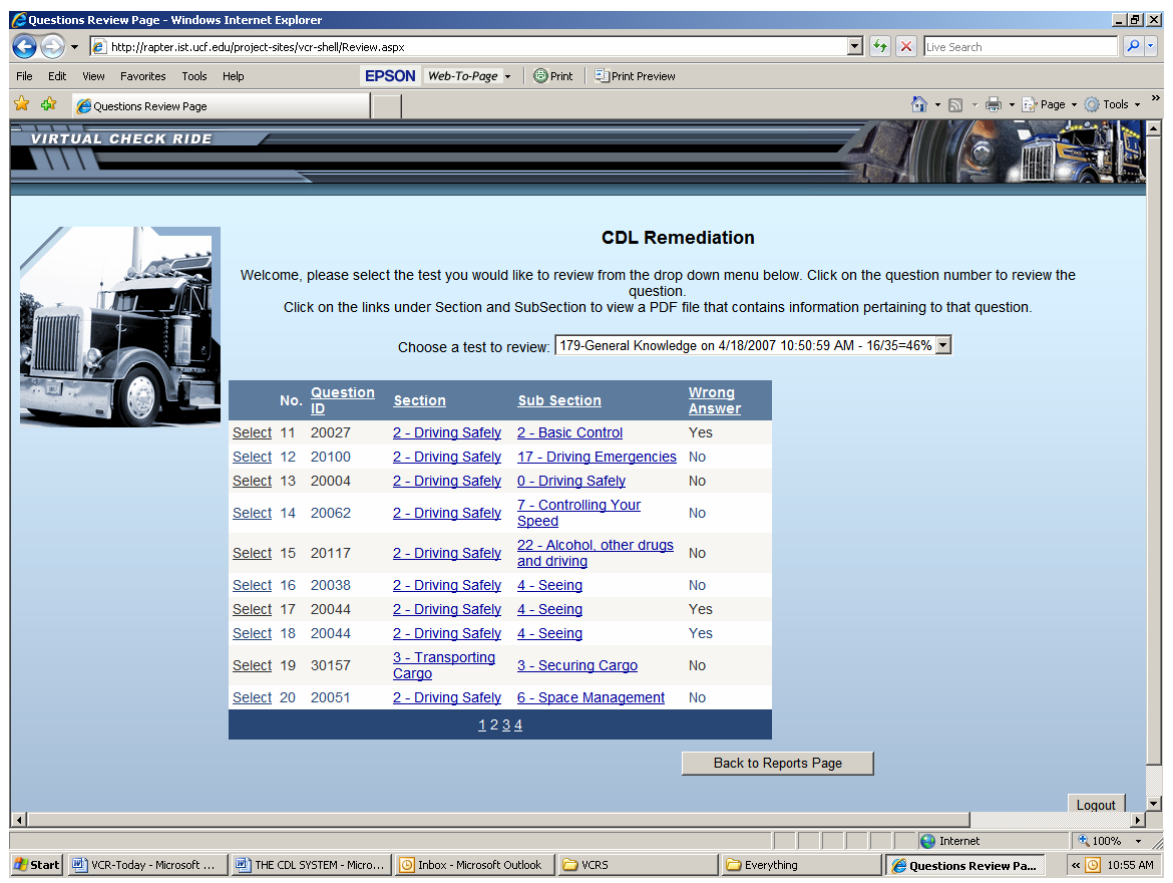

Figure 3. CDL Remediation

\section{VALIDATION PROCESS}

This investigation was conducted at large trucking firms and a nation-wide truck driving school. The apparatus for this investigation utilizes the TranSim $\mathrm{VS}^{\mathrm{TM}}$ truck-driving one-channel and three-channel truck driving simulators. The VCR knowledge and diagnostic test is then administered, followed by several simulated truck driving scenarios via the simulators.

\section{PARTICIPANTS}

The one-channel simulator novice group included 26 drivers (RoadMaster Truck Driving Students: $n=26$, mean age of 35 , with a mean of 17 days of driving experience) who were in their second week of training, the experienced one-channel simulator group included 52 drivers (Fritolay $n=52$ mean age is 41.5 with a mean of 15 years of driving experience) and a threechannel simulator novice group including 50 drivers from Schneider International in their second week of training. Tasks comparison included stop line maneuver, straight line backing, alley docking using a one-channel simulator and alley docking using a one-channel and a threechannel simulator. 


\section{RESULTS}

The stop line maneuver consists of the driver pulling forward through a lane of orange cones or orange stop sticks approximately the length of the truck and placing his or her front bumper in a small rectangular box at the end of the lane. The completion rate for the exercise (successfully placing the bumper in the stop box) was $98 \%$ for the experienced drivers and $100 \%$ for the novice drivers. The participants for this exercise included the one-channel novice and experienced groups (Figure 4).

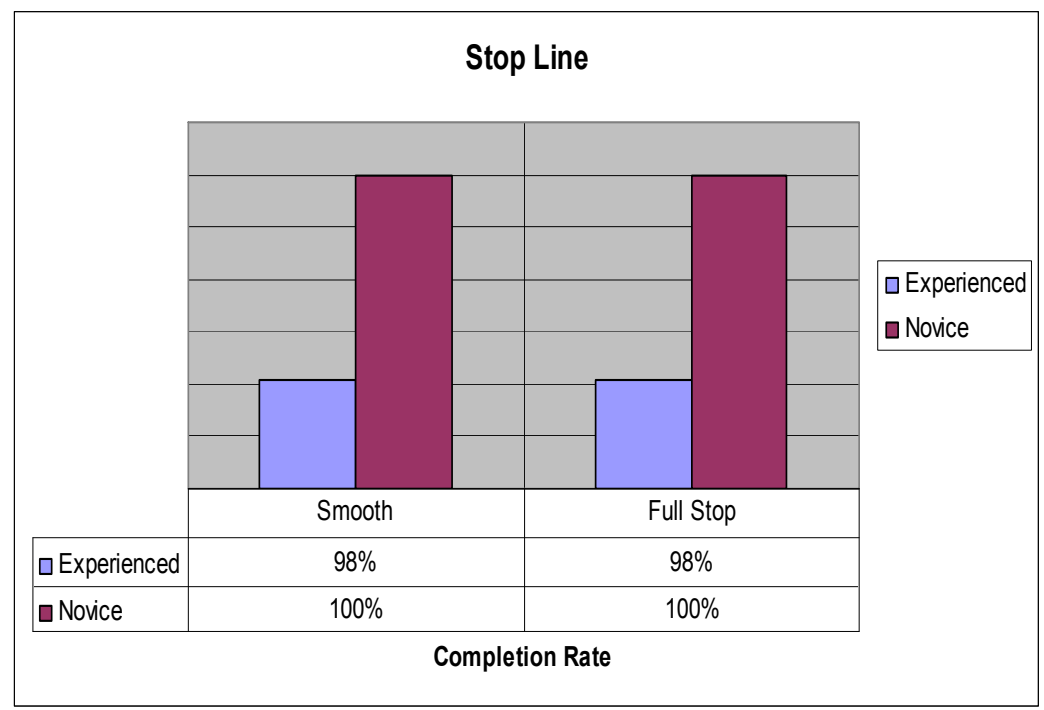

Figure 4. Stop Line Maneuver

The straight line back consists of the driver backing through a lane of orange cones approximately the length of the truck until the nose of the tractor clears the last cone. "Smooth" refers to the ability of the driver not to unnecessarily jerk the truck by unnecessary acceleration or braking. "Used mirrors" refers to or asks does the driver consistently scan the mirrors while backing. During a straight line back a driver should have the transmission in low reverse and simply idle back; it should take no additional acceleration. The participants for this exercise included the one-channel novice and experienced groups (Figure 5). 


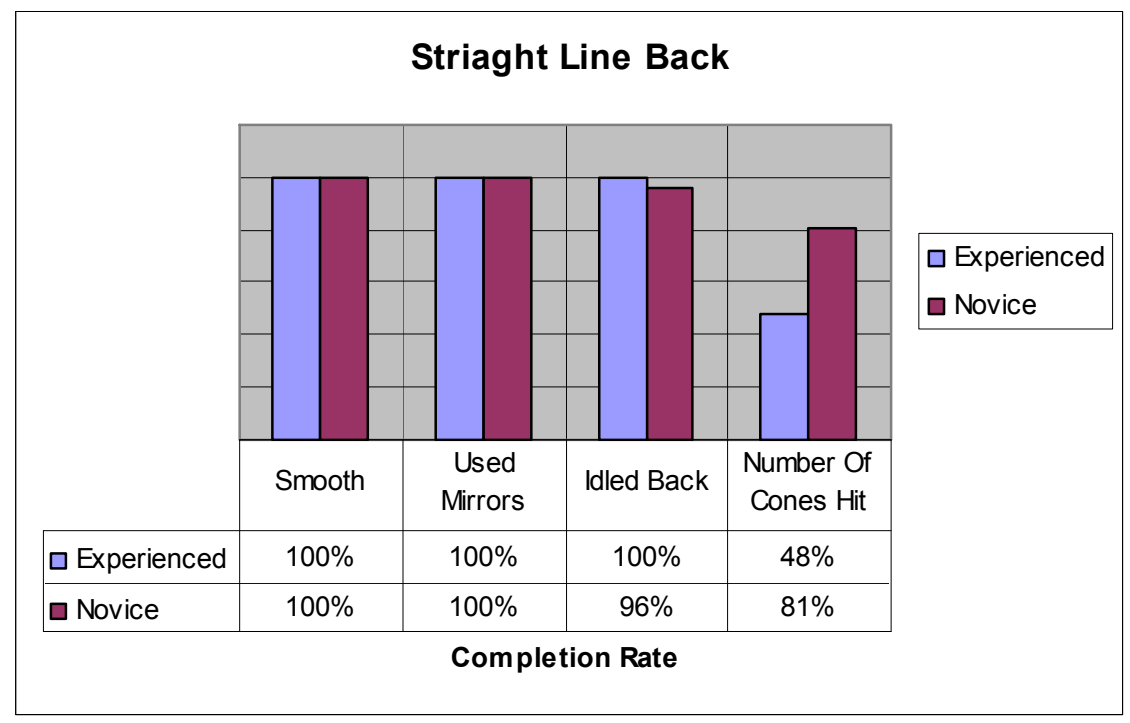

Figure 5. Straight Line Back

The alley dock maneuver consists of the driver pulling forward and positioning his or her truck correctly in order to make a 90-degree driver's side back into a set of cones that simulate a dock. The completion rate for the exercise (successfully placing the bumper in the stop box) was $98 \%$ for the experienced drivers and $100 \%$ for the novice drivers. The participants for this exercise included the one-channel novice and experienced groups (Figure 6).

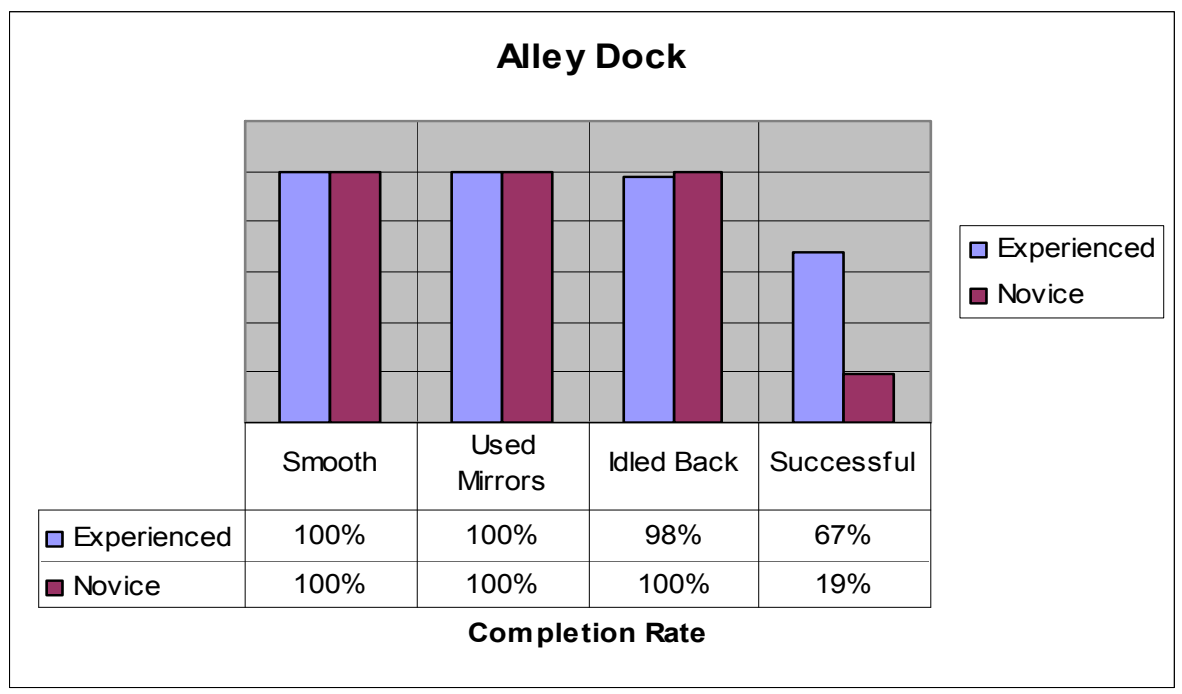

Figure 6. Alley Dock

One among many interesting findings is the performance outcome these groups demonstrated in the alley dock. The performance measure is success, defined as the back of the truck being flush to a dock for the purpose of unloading freight (absolutely essential skill in driving). The experienced 1 and novice 3 group both had a 67\% success rate, while the novice 1 group had a 
$19 \%$ success rate. The participants for this exercise included the one- and three-channel novice groups and the one-channel experienced group (Figure 7).

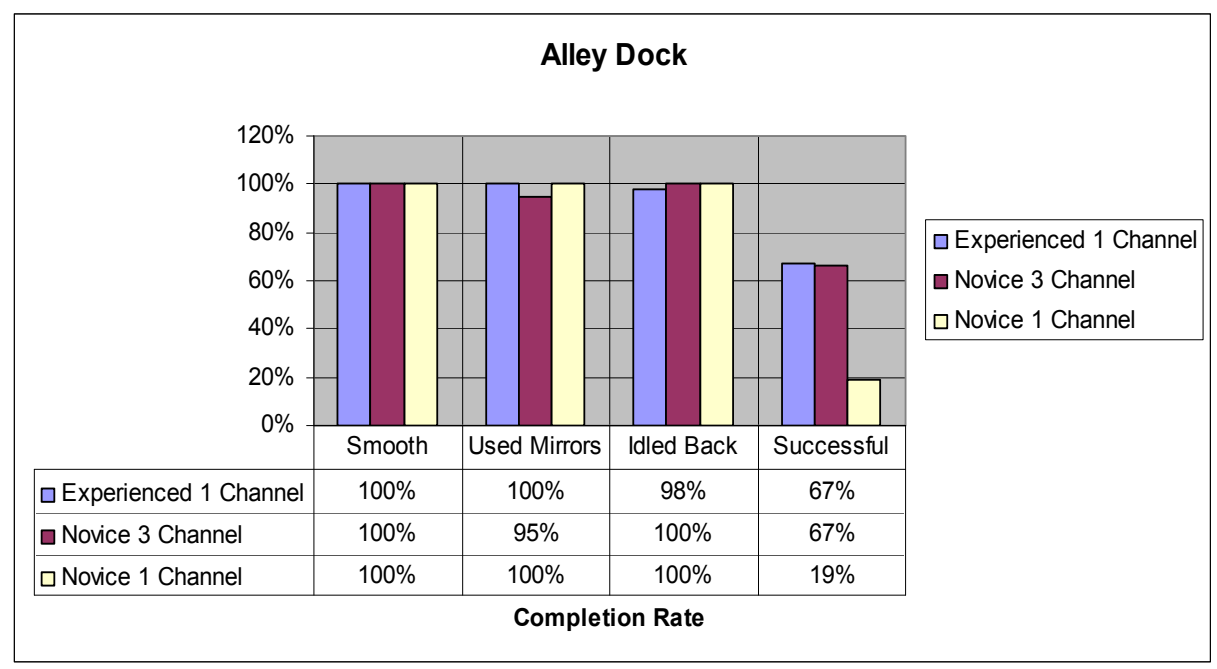

Figure 7. Differences in Simulators

\section{CONCUSION}

From this validation effort, it is clear that certain tasks can be accomplished with the one-channel simulator (stop line and straight line back); however, it is clear from Figures 6 and 7 that a onechannel simulator is inappropriate for use in the CDL Class A driver's test. The three-channel novice group that was in the second week of training, compared to the one-channel novice group in the second week of training, had a success rate of $67 \%$ vs. 19\%, respectively. The alley dock can not be accurately represented using the one-channel simulator. Thus, we suggest that for accurate testing of a driver trainee, or for the use of the VCR, a three-channel simulator is required.

\section{REFERENCES}

Tarr, R.W., Kincaid, P. Long, J.J., \& McCloy, A. (2002). Technical and Cost Proposal. Validation of a Simulation Based Re-Certification of the Commercial Driver License. The Virtual Check Ride.

Sanders, J.R. (1994). The Program Evaluation Standards, How to Assess Evaluations of Educational Programs, $2^{\text {nd }}$ Edition. New Delhi London, England: Sage Publications.

State of Florida. (1998). CDL Test Validity and Reliability.- CDL Handbook.

Thomas, R., \& Hooper, E. (1991). Simulations: An Opportunity We Are Missing. Journal of Research on Computing in Education. 23(4), 497-513. 